\title{
Optimize the application of micro-class in college English teaching
}

\author{
Zhang Gao \\ (Sichuan Vocational \& Technical College Sichuan Suining 629000) \\ Project: The design and application of Micro class about public English in Vocational \& Technical College \\ Number of the project: 16 SB0296
}

Keywords: Optimization, micro - class, application, college English, teaching, thinking

\begin{abstract}
Micro-class is a new way of teaching, by more and more educator attention. Under the background of "informationization", it is of great practical significance to introduce micro class into college English teaching. Its unique advantages and English language learning is very fit, throughout the teaching and learning process, promote the role of teachers and students to change and optimize. Micro-class with its short and pithy, targeted features can be flexibly applied to all aspects of college English teaching. We combine micro-class with research-based teaching, and focus on how to promote research-oriented teaching of college English better through the new teaching resources like micro-class.
\end{abstract}

\section{Introduction}

In recent years, with the advancement of college English curriculum reform, research-based teaching is receiving more and more attention from the educational circles. This kind of teaching thought, teaching mode and teaching method that accomplishes the discipline teaching task through initiating, promoting, supporting and guiding the research activities of the students by the teacher is a major change of the teaching idea in essence. "College English Curriculum Requirements" pointed out that the new teaching model should reflect the practical teaching of English, knowledge and interest of combining the principle. We should fully mobilize the enthusiasm of both teachers and students, in particular, to establish the dominant position of students in the teaching process.

The rapid development of information technology has quietly come to micro era, micro-class is precisely in this context came into being. Micro-class use of micro-video as a teaching resource for students to learn to use their short and pithy, targeted features are also welcomed by the majority of educators and students. This article attempts to combine the micro-class with the research-oriented teaching, and focuses on how to promote the research-oriented teaching of college English better through the new teaching resources like micro-class.

In the era of rapid development of mobile terminals and the Internet, China's higher education is confronted with the traditional methods of education, and learning methods can not meet the current needs of individualized and diversified learning. Speeding up the construction of informationization will be one of the important ways to solve such contradictions and the reform of higher education. Among the many educational information resources, "Micro-Class" is adhering to the concept of opening up and sharing education resources and is gradually emerging in the world. Its characteristics of high efficiency, convenience, fragmentation, mobility and strong interaction have broken the limitation of time and space in the traditional teaching mode and cater to the requirements of the times and the learning habits of the general public. It will become one of the courses in the information age. The application of "micro-class" to college English teaching will conform to the development of the times and the change of students 'learning mode, and will be a useful supplement to classroom learning, which will help improve students' interest in learning and learning. 


\section{The Proposed Methodology}

Micro-class concept. Micro-class refers to the teaching of video as the main carrier to PPT software as the main technical support, recording teachers around a knowledge point or teaching links to carry out a brief and complete teaching activities. It is to explain a certain point of knowledge as the main task, with short and refined video as the manifestation, the main content of the teaching video for teachers, supplemented by teaching design, material courseware, practice testing, peer reviews. Therefore, the micro-class is not a single type of traditional teaching resources, but an open, relatively complete and comprehensive new teaching resource.

As early as the 1960s, the affiliated school of Alvaghua University proposed the concept of Minicourse, and its research tended to focus on the development of short courses. Since the 21st century, more and more attention has been paid to the study of "micro-class" and "mini-video" in foreign countries. Some mini-class videos featuring large-scale and unique influences the world's basic education. In China, a series of micro-class events organized by the Ministry of Education and the Educational Technology Association have promoted the development of micro-class in the fields of basic education and higher education in China. However, the study of micro-class in our country is still in the initial stage, the research direction is mainly the macro-area, the practice object is concentrated in the primary and secondary basic education stage, the field of application and the applied research in universities are still not enough.

Micro-class features. Micro-class is different from the boutique course, but also different from the demonstration course, it has the relative independence and integrity of knowledge and other characteristics. Require teachers to explain a clear knowledge of a point in a short time, thorough, so that learners easy to understand compared to "Professor" is more inclined to "puzzle."

Video as the core carrier, resources, diverse. Knowledge points are recorded as mini-video videos in the form of teacher-professors, supplemented by instructional design, multimedia material, teaching reflections after class, feedback from students and reviews by academic experts to form relatively independent and complete teaching resources for learning Watch, learn.

Prominent theme, short and pithy. Micro-class video to about ten minutes is appropriate, mainly to highlight the teaching of a subject knowledge points (such as the teaching of the key, difficult, doubtful content) teaching, or reflect a classroom teaching, teaching topics Teaching and learning activities, mainly for students preview, after-school review.

Easy to acquire, suitable for dissemination. Micro-class is not a course of teaching, but rather in a limited time on a knowledge point to explain more carefully, so that viewers in a short period of time interested in video content and basic understanding or grasp of the content. Resources such as video are easily accessible and disseminated, and audiences can watch, learn or share with others who have the same needs, when needed.

The Significance of Applying Micro-class to College English Teaching. In the era of rapid development of information technology, as a form of high quality educational resources for higher education, micro-class has been universally popularized and adopted worldwide, and will have an impact on the reform of higher education. The teaching of college English undertakes the important mission of internationalization of higher education. It should be in line with the development of the times and the forefront of education reform and the construction of a clear, flexible and informative micro-class college English, with very important practical significance.

The development of modern information technology changes people's educational concepts, learning methods and reading modes. With the support of the Internet and mobile terminals, people get information quickly and efficiently, and messages are used to fragmentation and ubiquitination.

The Internet has entered a "micro" era, and "microblogging", "WeChat" and "micro video" have quietly emerged and gradually become a kind of people's life style and are realized through mobile terminals. There are also many front-line teachers around us that move the network to take away at least half of the students' attention, students are much more concerned about the phone than the textbooks, teachers use traditional mode to explain a few paragraphs or knowledge students do not listen Go on What is more, some students may not have any books related to the course materials, but indispensable to mobile phones and other electronic communication tools to finish a lesson. 
Students who grew up in the information age are more receptive to the digital learning model and tend to accept information that is selective, concise and easy to understand, diverse in form and combines knowledge and fun. If educators still adhere to the traditional teaching model, using old and stereotyped concepts to teach knowledge is bound to cause the contradiction between teaching and learning. Micro-class as a product of "micro" era of educational resources with a micro-righteousness to small advantage, in learning and reading mode also fit the mentality of the present learners.

The transformation of informatization education mode impels the deep transformation of education system, so does the teaching reform of college English. The traditional college English teaching mode which mainly consists of classroom teaching, learning, interactive discussion and after-school exercises cannot meet the needs of pursuing individualization, fragmentation and ubiquitous learning. Teachers' lectures are often informative and long enough to be accepted by students, and the students feel boring and tired at the end of the course while on the contrary, with QQ, WeChat and other applications published in all types of English articles, video, no lack of followers and forwarders, and more popular. As a result, micro-class as the delivery of knowledge to become a new era of an innovative teaching method to meet the learning needs of learners.

The introduction of teaching in microcosms can promote the transformation of the concept of college English teaching. Any teaching reform should be guided by advanced concepts and advanced concepts must reflect the characteristics of the times. Unable to adapt to the development of information age college English teaching reform can only be in the original teaching system minutiae changes, less than the desired effect. The research and construction of micro-class will further highlight the main task of teaching English as a center, update the teaching concepts and knowledge structure of teachers of different ages to adapt to the learning needs of social development and changed learners, Teaching to keep up with the requirements of the times.

Micro-class teaching can promote the reform of college English course content and curriculum system. The reform of college English teaching not only needs to improve the curriculum, curriculum structure and evaluation system, but also change the teaching methods of teachers and the ways of students' learning. With the convenience of modern information technology, micro-class integration of superior teaching resources and refinement of knowledge structure help to enrich teachers 'teaching methods and change learners' roles. The construction of college English series of micro-class can diversify English teaching resources and promote the reform of the curriculum content and system.

New teaching relationship. In college English teaching, most colleges and universities use multimedia teaching, teaching teachers to teach classes in large classes. I heard class to complete the book exercises, supplemented by unit theme supplementary materials. Reading and writing classes generally analyze texts, teach cultural backgrounds, analyze writing characteristics and practice after class. A large number of knowledge points in the form of PPT, subject to class restrictions, lecturers often teach too fast, difficult for students to digest understanding. The teaching methods are single, the interest in learning of students gradually diminishes, and teachers are not motivated in teaching. In the long run, the learning effect is greatly reduced. Teachers in the micro-class teaching process are not only the imparters of knowledge, but also the leaders and deconstructionists. Teachers provide students with richer learning resources to meet their diversified learning needs and guide them to deep-seated and individualized Learn and explore. This learning model can develop students 'autonomous learning ability and research ability, and also help to promote the change of teachers' roles and closer the relationship between teachers and students.

In order to be able to change the status quo of professional English teaching in higher vocational colleges, to improve students 'interest in learning, to promote the improvement of teachers' teaching ability and to promote the integration of information technology and subject teaching, it is beneficial to use the micro-class in college English teaching Try, it will also produce good results.

Micro-class in college English teaching can have a variety of purposes, to explain the focus of the text and new knowledge points, review has been difficult to answer students' questions and so on. Micro-class can be used in class to help explain the point of knowledge, but also can be used as a preview of students, review of learning materials. 
Used in classroom teaching aids. Teachers can integrate content that can not be found in the classroom and edit them into diverse micro-class videos that are easily understood by students so that they can be stimulated and trained in everything from listening, speaking and reading. Micro-class video can also be shared in similar courses, to a certain extent, the balance of high-quality educational resources. Teachers can also modify or improve a certain part of the video according to their own understanding, and constantly update the content of the micro-class so as to keep the use of language in line with the development of the times. This can make the classroom teaching form flexible and full of vitality, and at the same time set up platforms for teachers to learn and communicate with each other and help teachers improve their teaching abilities.

Used in class preview or after class review, combined with the flip class. This kind of application mode needs to make the teaching content of the micro-lesson heuristic or summary. Relatively limited time, college English teaching task is larger. How to balance the pre-class import, explain in class, after-school practice time for some teachers are a problem, in many cases, teachers need to choose the teaching content to complete the teaching task.

Quickly cut into the theme, take multi-modal teaching mode. Due to the time limit of the micro-class, teachers should cut into the subject in the shortest time so that the students can see at a glance and avoid excessive importation. Compared with the face-to-face teaching, it is more difficult for teachers to control the actual learning situation of the students. For example, the content of the professor is dull and the effect is lost. Teachers can choose multi-modal teaching mode to make the teaching flexible in content and form.

\section{Conclusion}

As a new teaching resource, micro-class can become an efficient and convenient teaching aid in the research teaching of college English. Micro-class can save classroom teaching time, you can watch repeatedly; Micro-class can give students a greater autonomy, enabling students to learn in depth, and in the process of learning in depth to develop and discover problems, analyze problems and solve problems. In a sense, micro-teaching and research-based teachings are closely linked. Micro-class teaching is still a new thing in college English teaching. The idea of micro-class into the research of college English teaching, in fact, the Ministry of Education in response to the requirements of the college English curriculum, reflecting the main trend of the future curriculum reform. Such teaching can give full play to and make use of the specialties of teachers and provide more choice opportunities for students so as to make students' autonomous study and research study get better.

\section{References}

[1]. Crookes, G., 2017. Critical Language Pedagogy Given the English Divide in Korea: A Suite of Practices, Critique, and the Role of the Intellectual. English Teaching, 72(4).

[2]. Dutton, J.L., 2017. English teachers in the making: Portraits of pre-service teachers’ journeys to teaching.

[3]. Zhou, Z., 2017. The Model Construction of English Ecological Class in the High School in China. English Language Teaching, 10(9), p.227.

[4]. Medwell, J., Wray, D., Minns, H., Griffiths, V. and Coates, L., 2017. Primary English: Teaching theory and practice. Learning Matters. 